\title{
The impact of transcutaneous posterior tibial nerve stimulation in patients with premature ejaculation
}

\author{
Mustafa Murat Aydos $\odot$, İdris Nas $\odot$, Efe Önen $\odot$ \\ Department of Urology, University of Health Sciences, Bursa Yüksek İhtisas Training and Research Hospital, Bursa, Turkey
}

\section{ABSTRACT}

Objectives: Approximately 30-40\% of men worldwide are affected by premature ejaculation. Despite much research on this subject, there is still little information about the cause and treatment of premature ejaculation. The aim of this study was to evaluate the therapeutic aspect of transcutaneous posterior tibial nerve stimulation (PTNS) in patients with premature ejaculation.

Methods: The study included 60 PE patients, aged 20-50 years, divided into 2 groups as the treatment group $(n=30)$ and the control group $(n=30)$. Transcutaneous PTNS was applied to patients in the treatment group for 30 minutes once a week for 12 weeks. In the control group, a stimulation probe was placed on the posterior tibial nerve without giving any stimulation, to provide a placebo effect. The Arabic Index of Premature Ejaculation (AIPE) scale and Intravaginal Ejaculation Latency Time (IELT) measurements were used before and after the procedure.

Results: In both groups, the mean IELT duration and AIPE scale scores were statistically significantly increased after the procedure $(p<0.05)$. The percentage change in the AIPE scale scores after the procedure was found to be higher in the treatment group than in the control group $(p=0.007)$.

Conclusions: The results of the study showed a statistically significant increase in the duration of the time to ejaculation with PTNS, and a significant improvement was obtained in the post-treatment AIPE scale scores. There is a need for further research to achieve more robust results to contribute to premature ejaculation treatment.

Keywords: premature ejaculation, posterior tibial nerve stimulation, sexual disorder, male

$\mathbf{P}$ remature ejaculation $(\mathrm{PE})$ is the most common male sexual disorder and is estimated to affect up to $30 \%-40 \%$ of men worldwide [1-3]. Despite much research on the subject, there is still limited knowledge about the etiology, diagnosis, pathophysiology and treatment of PE. The International Society for Sexual Medicine (ISSM) adopted a new definition of PE in 2014 [4]. According to this definition, the main problem is the inability to delay ejaculation (short intravaginal ejaculation latency time (IELT), defined as the time between the start of vaginal intromission and the start of intravaginal ejaculation, frequently used as definition of PE with IELT $<1$ min), resulting in distress, frustration, and/or the avoidance of sexual intimacy.

Pelvic floor muscle training has been shown to have a role in the treatment of many urological problems (e.g. lower urinary tract symptoms, urinary in- 
continence, erectile dysfunction and premature ejaculation). These studies have revealed that contraction of the male pelvic floor muscles (i.e., bulbospongiosus and ischiocavernosus) via neuromuscular electrical stimulation can be safely performed for several minutes, with good perception and without discomfort. As ejaculation involves rapid stereotyped rhythmic contractions of the bulbospongiosus and ischiocavernosus muscles, inhibiting this type of contraction may have a beneficial effect in the treatment of PE [5].

The aim of this study was to evaluate the therapeutic aspect of transcutaneous posterior tibial nerve stimulation (PTNS) in patients with PE.

\section{METHODS}

This prospective study included patients aged 2050 years, diagnosed with PE between June 2015 and June 2016. Patients with cardiac failure, arrhythmia, skin scarring, sexual dysfunction other than premature ejaculation, urogenital anatomic disorder, oncology patients, and those unwilling to participate in the study were excluded. All participants provided written informed consent. The patients were divided into 2 groups as the treatment group and the control group. Demographic data of the patients were recorded, then the Arabic Index of Premature Ejaculation (AIPE)

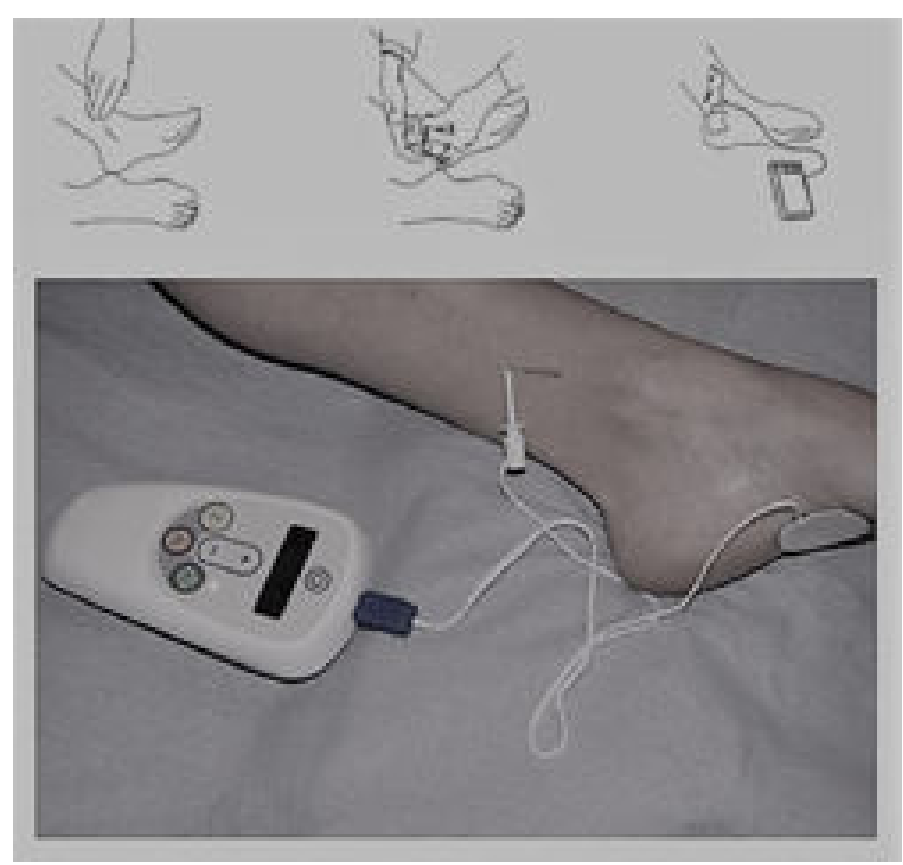

Fig. 1. Treatment with electrical stimulation scale was used to evaluate both the diagnosis and the severity of PE. The AIPE is a 7-item questionnaire that evaluates sexual desire, hard erections for sufficient intercourse, time to ejaculation, control, satisfaction for the patient and partner, and anxiety or depression. The scale has been validated for use in the Turkish population $[6,7]$. Patients were informed about how to perform the IELT measurement using a chronometer and the patients were asked to record the ejaculation times before and after treatment using the chronometer. Transcutaneous posterior tibial nerve stimulation was applied to the 30 patients in the treatment group, for 30 minutes once a week for 12 weeks. Electrical stimulation was applied with the Pagani ET10 ${ }^{\circledR}$ electrotherapy device (Pagani Elettronica, Italy) using $200 \mu \mathrm{sec}$ pulses with a pulse rate of $20 \mathrm{~Hz}$ (Fig. 1). In the control group, a placebo effect was provided by a stimulation probe placed on the track of the posterior tibial nerve without giving any stimulation. All data on the AIPE forms and the recorded IELT times measured using a chronometer were compared before and after the treatment procedure.

This prospectively designed study complied with the Declaration of Helsinki, regulations involving patient's rights and ethical guidelines and was approved by the Local Ethics Committee (approval number: 2011-KAEK-25-2015/11-01).

\section{Statistical Analysis}

Data were analyzed using SPSS (Statistical Package for the Social Sciences) v.23 software (SPSS Inc, Chicago, IL, USA). The descriptive statistics for the numerical variables were expressed as mean \pm standard deviation, and as number and percentage for categorical data. After assessment of the conformity of the data to normal distribution, the paired t-test was used to compare the dependent samples and the MannWhitney U-test was used to compare the independent variables. The results were evaluated at $95 \%$ confidence interval and a value of $p<0.05$ was considered statistically significant.

\section{RESULTS}

Eighty-two patients with PE included in the study. However, because of noncompliance to transactions, 
Table 1. Evaluation of mean AIPE scores and IELT before and after treatment in the patient and control groups

\begin{tabular}{|c|c|c|c|c|c|}
\hline & \multicolumn{2}{|c|}{ AIPE } & \multirow[t]{2}{*}{$p$ value } & \multicolumn{2}{|c|}{ IELT (sec) } \\
\hline & Pre-treatment & Post-treatment & & Pre-treatment & Post-treatment \\
\hline $\begin{array}{l}\text { Treatment Group } \\
(\mathbf{n}=\mathbf{3 0})\end{array}$ & $16.55 \pm 4.74$ & $21.4 \pm 4.98$ & 0.001 & $40.4 \pm 13.21$ & $51.25 \pm 10.5$ \\
\hline $\begin{array}{l}\text { Control Group } \\
(\mathbf{n}=\mathbf{3 0})\end{array}$ & $18.2 \pm 5.2$ & $20 \pm 4.65$ & 0.001 & $37.9 \pm 11.81$ & $42.5 \pm 11.64$ \\
\hline
\end{tabular}

22 patients were excluded. The mean age of the patients was $34.85 \pm 6.29$ years in the treatment group $(\mathrm{n}=30)$ and $31.85 \pm 6.02$ years in the control group $(\mathrm{n}=30)$, with no statistically significant difference determined between the groups $(p=0.132)$. In the treatment group, the AIPE mean score was $16.55 \pm$ 4.74 pre-treatment and $21.4 \pm 4.98$ after the procedure. This increase in AIPE mean scores from pre to post treatment was statistically significant $(p<0.001)$. In the control group, the AIPE mean score was $18.2 \pm 5.2$ before the procedure and $20 \pm 4.65$ after the procedure and this increase was determined to be statistically significant increase $(p=0.001)$ (Table 1). The percentage change in the pre to post-procedural AIPE scores was $0.33 \pm 0.26$ in the treatment group and 0.13 \pm 0.16 in the control group. There was a statistically significant difference between the treatment and control groups in terms of percentage change in AIPE scores after the procedure $(p=0.007)$ (Table 2).

In the patient group, the mean IELT was $40.4 \pm$ $13.21 \mathrm{sec}$ pre-treatment and $51.25 \pm 10.5 \mathrm{sec}$ posttreatment. The increase in mean IELT from pre- to post-treatment was statistically significant $(p<0.001)$. In the control group, the mean IELT was $37.9 \pm 11.81$ sec before the procedure and $42.5 \pm 11.64 \mathrm{sec}$ after the procedure, and the increase was statistically significant $(p=0.030)$ (Table 1). The percentage change in preto post-procedural IELT scores was $0.38 \pm 0.47$ in the treatment group and $0.23 \pm 0.67$ in the control group. No statistically significant difference was determined between the patient and control groups in terms of percentage change in IELT scores from pre to postprocedure $(p=0.415)($ Table-2).

Table 2. Comparison of mean AIPE scores and mean IELT durations before and after treatment in the patient and control groups and assessment of the percentage change rates of AIPE scores and IELT after treatment

\begin{tabular}{lccc}
\hline & $\begin{array}{c}\text { Treatment Group } \\
(\mathbf{n = 3 0 )}\end{array}$ & $\begin{array}{c}\text { Control Group } \\
(\mathbf{n = 3 0 )}\end{array}$ & $\boldsymbol{p}$ value \\
\hline $\begin{array}{l}\text { AIPE scores before } \\
\text { treatment }\end{array}$ & $16.55 \pm 4.74$ & $18.2 \pm 5.2$ & 0.301 \\
$\begin{array}{l}\text { \% change of AIPE } \\
\text { scores after treatment }\end{array}$ & $0.33 \pm 0.26$ & $0.13 \pm 0.16$ & $\mathbf{0 . 0 0 7}$ \\
$\begin{array}{l}\text { IELT before } \\
\text { treatment (sec) }\end{array}$ & $40.4 \pm 13.21$ & $37.9 \pm 11.81$ & 0.532 \\
$\begin{array}{l}\text { \% change of IELT } \\
\text { after treatment }\end{array}$ & $0.38 \pm 0.47$ & $0.23 \pm 0.67$ & 0.415 \\
\hline
\end{tabular}

Data are shown as mean \pm standard deviation. AIPE $=$ Arabic Index of Premature Ejaculation, IELT $=$ Intravaginal ejaculation latency time 


\section{DISCUSSION}

PE with a prevalence of $4 \%$ to $39 \%$ in all populations is ranked first among male sexual dysfunctions, with a negative impact on the social life of both the individual and their partner. Psychological, environmental, endocrine and neurobiological factors have been shown to be effective in the etiology. However, the highly variable and complicated etiology has not yet been fully clarified $[1,8]$.

Age is undoubtedly a risk factor for erectile dysfuction, whereas for PE the opposite is true. PE is observed more frequently in younger men, and the risk decreases with age. Researchers have explained that this reduction is achieved through more relevant experience, and learning appropriate techniques and positions, and it has been emphasized that young men may not be able to sufficiently control ejaculation [9]. Therefore, the mean age of $34.85 \pm 6.29$ years for the $30 \mathrm{PE}$ patients in treatment group of this study was found to be consistent with these published data.

PE leads to a decrease in general well-being, loss of self-esteem, feelings of shame and inferiority, depression and anxiety. In a previous study, selfesteem related to $\mathrm{PE}$ was found in $68 \%$ and anxiety in $36 \%$ of patients [10]. Dunn et al. [11] also reported that the relationship between PE and anxiety affected the man's quality of life. Patrick et al. [12] reported sexual satisfaction at $31 \%$ and personal stress at $64 \%$ in men with $\mathrm{PE}$ and these rates were determined to be statistically significantly higher than those of non-PE cases. The AIPE scale includes key items related to both the mental status of the patients and erectile dysfunction. In a study of 1,608 applications made to a urology polyclinic due to urological complaints, $20.8 \%$ of the complaints were reported to be related to PE. It was also stated that $16.2 \%$ of these cases did not want treatment for reasons such as not considering this to be a problem, feelings of shame or for economic reasons $[13,14]$. However, with the decline in quality of life, patients begin to seek treatment, such as focusing on another topic during the relationship, stopping for a while and resuming the relationship, pre-relationship masturbation, more frequent relationships, drinking alcohol pre-relationship or taking pleasure from other items. Current treatments for PE include behavioral treatments (stop-start and squeeze methods), topical treatments, PDE5 (phosphodiesterase type 5) inhibitors, tramadol, selective serotonin reuptake inhibitor (SSRI), dapoxetine, oxytocin, hyaluronic acid application, dorsal penile nerve cryoablation, intracavernosal injection, acupuncture, botulinum neurotoxin, surgical treatment options and pelvic floor rehabilitation [1517].

According to current guidelines, the first step in PE treatment consists of oral antidepressants and topical anesthetics. Over time, SSRI and clomipramine in particular have become the first choice for PE treatment [16, 17]. Abdel-Hamid et al. [18] reported that antidepressants (clomipramine, sertraline, paroxetine) are equally effective in themselves and paroxetine is more effective than the "stop-squeeze" method and other antidepressants. However, SSRIs have a risk of accumulation, and when the dose increases, the side effects also increase. Side-effects can be very dangerous because of serotonin syndrome, myoclonus, hyperreflexia, sweating, impaired coordination and changes in mental status. Sexual side-effects including erection loss and decreased libido can be seen. An increase in suicide and self-harm tendency has been reported in SSRI users. Since PE is not a life-threatening event, benefit and risk analysis should be performed for SSRI treatment [17]. In a randomized, placebo-controlled study, Busato and Galindo [19] applied topical anesthetic cream (lidocaine-prilocaine solution) to 42 PE patients and as a result they found that mean IELT time (8.49 min) was significantly higher than mean IELT time (1.49 $\mathrm{min}$ ) before application. However, topical treatments can cause vaginal numbness and anorgasmia if the glans penis is not washed well, and can cause drowsiness and erection of the penis when it is expected to be over 45 minutes after application. Skin reactions can develop on the penis and vagina [17]. Tramadol is not recommended for long-term treatment of PE. A decrease in the efficacy of tramadol has been reported after 12 weeks of treatment, which causes a need to increase the dose, and there is the risk of opioid addiction [20]. Treatments such as dorsal penile nerve cryoablation increases IELT but is an invasive and irreversible treatment [17]. The continuous use of these medical treatments results in restriction of activities, often not being able to meet expectations, low patient compliance, persistence, side-effects and even irreversible effects, and therefore 
the necessity for alternative medicinal treatment modalities has increased in recent years [16]. Thus, the aim of this study was to investigate the efficacy of transcutaneous posterior tibial nerve stimulation as a placebo-controlled treatment as an alternative treatment option in patients with PE.

In a meta-analysis by Waldinger et al. [21], 79 studies (total 3034 cases) were evaluated in respect of methodology by searching $\mathrm{PE}$ in the scientific literature. It was emphasized that studies that measured IELT duration with the stop-watch method fulfilled the criteria more effectively [18]. In the current study, the stop-watch method was used to measure real-time IELT, as recommended by Waldinger et al. [21].

Glans penis hypersensitivity and hyperexcitability have been reported repeatedly in patients diagnosed with PE, which has been confirmed in somatosensory evoked potential studies. It is believed that this leads to organic consequences for ejaculation and $\mathrm{PE}$, which cannot be controlled in patients. It is known that ejaculation occurs predominantly on the basis of stimulating spinal pathways, but inhibitor spinal inputs are also present [22]. To date, many electrical stimulation techniques such as sacral and pudendal neuromodulation, pelvic wall rehabilitation, electroejaculation, and acupuncture have been used for various sexual dysfunctions [23-25]. Tibial nerve stimulation, which was applied in the current study, involves many anatomic similarities to the technique used in somatosensory evoked potential studies. To date, in addition to use in the treatment of overactive bladder syndrome, transcutaneous electrical nerve stimulation (TENS) has been widely used for the treatment of back and neck pain, increased motor function and reflex movements, hemiplegia therapy, osteoarthritis pain treatment, rheumatoid arthritis treatment, and some opioid peptides in CSF have been reported frequently in the literature [26]. In these studies, TENS was found to be clinically effective and superior to placebo [27-29]. In the current study, transcutaneous posterior tibial nerve stimulation was applied similar to the use of TENS in the treatment of overactive bladder syndrome.

Many studies in the literature have described the use of acupuncture in sexual dysfunction treatments. Sunay et al. [30] applied medical treatment (paroxetine), acupuncture, and a placebo effect in the form of acupuncture by dividing the PE patient into 3 groups. The increases in IELT durations of the paroxetine, acupuncture and placebo groups were 82.7 $\mathrm{sec}, 65.7 \mathrm{sec}$, and $33.1 \mathrm{sec}$, respectively. Although the increase in IELT was most prominent in the medical treatment group, the increase in IELT in the acupuncture group compared to the placebo group was statistically significant $(p<0.001)$ [30]. The presence of anterior tibial muscle, metatarsal bone, dorsal pedis artery, calcaneal tendon and medial malleolus in selected aqueduct points are remarkable in terms of anatomic application areas similar to those of the current study. Although the physiological mechanism of acupuncture is not very clear, it can accommodate the spinal segmental and suprasegmental inhibition theory. It is a known fact that electrical peripheral / posterior tibial nerve stimulation is based on the traditional Chinese practice of acupuncture [31]. In a prospective study, Geirsson et al. [32] compared the results of stimulation of the tibial nerve with acupuncture and TENS methods. This is important as through the results of that study, the data of the current study can be compared with the data obtained from acupuncture studies because there is no comparable study published in the literature related to PTNS treatment in PE patients.

Although we did not provide any electrical current on the control group in both IELT and AIPE index scores improved significantly. We think that the contact of the PTNS probe to the body procuded a placebo effect.

The current study can be considered of value as the first study in literature to have applied transcutaneous posterior tibial nerve stimulation as a treatment option in PE-diagnosed patients. Nevertheless, there is a need for further studies involving comprehensive and larger sample groups to obtain results which will contribute to the treatment of PE.

\section{CONCLUSION}

Currently, none of the recommended PE therapy options alone can satisfy the patients and their effectiveness remains limited. Therefore, more effective, reliable, easily applicable, long-lasting, and well-tolerated therapy options are being sought. The 
results of this study demonstrated that a statistically significant increase in the time to ejaculation was achieved by transcutaneus posterior tibial nerve stimulation. Furthermore, a significant improvement was obtained in scale scores after the procedure in patients diagnosed with PE. There is a need for further research with larger study groups to achieve more robust results to make an additional contribution to PE treatment.

\section{Conflict of interest}

The authors disclosed no conflict of interest during the preparation or publication of this manuscript.

\section{Financing}

The authors disclosed that they did not receive any grant during conduction or writing of this study.

\section{REFERENCES}

1. Laumann EO, Nicolosi A, Glasser DB, Paik A, Gingell C, Moreira E, et al. GSSAB Investigators' Group. Sexual problems among women and men aged 40-80 y: prevalence and correlates identified in the Global Study of Sexual Attitudes and Behaviors. Int J Impot Res 2005; 17:39-57.

2. Porst H, Montorsi F, Rosen RC, Gaynor L, Grupe S, Alexander J. The premature ejaculation prevalence and attitudes (PEPA) survey: Prevalence, comorbidities and professional help-seeking. Eur Urol 2007;51:816-24.

3. Laumann E, Paik A, Rosen R. Sexual dysfunction in the United States: prevalence and predictors. J Am Med Assoc 1999;281:537-44.

4. Serefoglu EC, McMahon CG, Waldinger MD, Althof SE, Shindel A, Adaikan G, et al. An evidence-based unified definition of lifelong and acquired premature ejaculation: report of the second International Society for Sexual Medicine Ad Hoc Committee for the Definition of Premature Ejaculation. J Sex Med 2014;11:1423-41.

5. Gruenwald I, Serefoglu EC, Gollan T, Springer S, Meiry G, Appel B, et al. Transcutaneous neuromuscular electrical stimulation may be beneficial in the treatment of premature ejaculation. Med Hypotheses 2017;109:181-3.

6. Arafa M, Shamloul R. Development and evaluation of the Arabic Index of Premature Ejaculation (AIPE). J Sex Med 2007;4:1750-6.

7. Serefoglu EC, Yaman O, Cayan S, Asci R, Orhan I, Usta MF, et al. The comparison of premature ejaculation assessment questionnaires and their sensitivity for the four premature ejaculation syndromes: results from the Turkish Society of Andrology Sexual Health Survey. J Sex Med 2011;8:1177-85.

8. Serefoglu EC, Saitz TR. New insights on premature ejaculation: a rewiew of definition, classification, prevalance and treatment. Asian J Androl 2012;14:822-9.

9. Montorsi F. Prevalence of premature ejaculation. A global and regional perspective. J Sex Med 2005;2:96-102.

10. Symonds T, Roblin D, Hart K, Althof S. How does premature ejaculation impact a mans life? J Sex Marital Ther 2003;29:36170 .

11. Dunn KM, Croft PR, Hackett GI. Association of sexual problems with social, psychological and physical problems in men and women. A crosssectional population survey. J Epidem Comm Health 1999;53:144-8.

12. Patrick DL, Althof SE, Pryor JL, Rosen R, Rowland DL, Ho KF, et al. Premature ejaculation: an observational study of men and their partners. J Sex Med 2005;2:358-67.

13. Erol H. Prematur ejakulasyon - Erektil disfonksiyon iliskisi. Androloji Bülteni 2006;25:102-5.

14. Malavige LS, Jayaratne SD, Kathriarachchi ST, Sivayogan S, Fernando DJ, Levy JC. Erectile dysfunction among men with diabetes is strongly associated with premature ejaculation and reduced libido. J Sex Med 2008;5:2125-34.

15. Littara A, Palmieri B, Rottigni V, Iannitti T. A clinical study to assess the effectiveness of a hyaluronic acid-based procedure for treatment of premature ejaculation. Int $\mathrm{J}$ Impot Res 2013;25:117-20.

16. Yavuz A, Serefoglu EC. Prematur ejakulasyon: Oral ve topikal ilaç dışı tedaviler. Androloji Bülteni 2011;17:102-5.

17. Metin A, Ozyalvaclı ME. Prematür ejakülasyon tedavisinde güncel yaklaşım. Androloji Bülteni 2016;18:4-7.

18. Abdel-Hamid IA, El Naggar EA, El Gilany AH. Assessment of as needed use of pharmacotherapy and the pause-squeeze technique in premature ejaculation. Int J Impot Res 2001;13:415.

19. Busato W, Galindo CC. Topical anaesthetic use for treating premature ejaculation: a double-blind, randomized, placebo-controlled study. BJU Int 2004;93;1018-21.

20. Raffa RB. Basic pharmacology relevant to drug abuse assessment: tramadol as example. J Clin Pharmacol 2008;33:1018.

21. Waldinger MD, Zwinderman AH, Schweitzer DH, Olivier B. Relevance of methodological design for the interpretation of efficacy of drug treatment of premature ejaculation: a systematic review and meta-analysis. Int J Impot Res 2004;16:369-81.

22. Xin ZC, Choi YD, Rha KH, Choi HK. Somatosensory evoked potentials in patients with primary premature ejaculation. J Urol 1997; 158:451-5.

23. Martellucci J. Electrical stimulation in sexual dysfunction. In: Martellucci J, editor. Electrical Stimulation for Pelvic Floor Disorders. Springer International Publishing: Switzerland, 2015: p. 201-23.

24. Escortell-Mayor E, Riesgo-Fuertes R, Garrido-Elustondo S, Asúnsolo-Del Barco A, Díaz-Pulido B, Blanco-Díaz M, et al. Primary care randomized clinical trial: manual therapy effectiveness in comparison with TENS in patients with neck pain. Man Ther 2011;16:66-73.

25. Deyo RA, Walsh NE, Martin DC, Schoenfeld LS, Ramamurthy S. A controlled trial of transcutaneous electrical nerve stimulation (TENS) and exercise for chronic low back pain. N Engl J Med 1990;322:1627-34. 
26. Levin MF, Hui-Chan CW. Relief of hemiparetic spasticity by TENS is associated with improvement in reflex and voluntary motor functions. Electroencephalogr Clinl Neurophysiol. 1992;85:131-42.

27. Kabay SKSC, Kabay SC. Posterior Tibial Sinir Stimülasyonu; Nasıl Yapıyorum, Sonuçlarımız. Kadın ve İşlevsel Üroloji Dergisi 2014;2:53-7.

28. Yurtkuran M, Kocagil T. TENS, electroacupuncture and ice massage: comparison of treatment for osteoarthritis of the knee. Am J Acupunct 1999;27:133-40.

29. Brosseau L, Yonge KA, Welch V, Marchand S, Judd M, Wells GA, et al. Transcutaneous electrical nerve stimulation (TENS) for the treatment of rheumatoid arthritis in the hand. Cochrane
Database Syst Rev 2003;(3):CD004377.

30. Sunay D, Sunay M, Aydogmus Y, Bagbanci S, Arslan H, Karabulut A, et al. Acupuncture versus paroxetine for the treatment of premature ejaculation: a randomized, placebocontrolled clinical trial. Eur Urol 2011;59:765-71.

31. Franco I. Pediatric overactive bladder and lower urinary tract dysfunctions: diagnosis and treatment. Pediatric Health 2008;2:189-203.

32. Geirsson G, Wang YH, Lindström S, Fall M. Traditional acupuncture and electrical stimulation of the posterior tibial nerve: a trial in chronic interstitial cystitis. Scand J Urol Nephrol 1993;27:67-70. 